\section{Effect of Brushing Time and Dentifrice Abrasiveness on Color Change and Surface Roughness of Resin Composites}

Lourenço de Moraes Rego Roselino, Michelle Alexandra Chinelatti, Carla

Cecilia Alandia-Román, Fernanda de Carvalho Panzeri Pires-de-Souza
Department of Dental Materials and Prosthodontics, Dental School of Ribeirão Preto, USP - Universidade de São Paulo, Ribeirão Preto, SP, Brazil

Correspondence: Profa. Dra. Fernanda de Carvalho Panzeri Pires-de-Souza, Avenida do Café, $s / n$, Bairro Monte Alegre, 14040-904 Ribeirão Preto, SP. Brasil. Tel: +55-16-3315-

3973. e-mail: ferpanzeri@usp.br

\begin{abstract}
Dentifrice abrasiveness and brushing time may increase color change $(\Delta \mathrm{E})$ and surface roughness $(\Delta R a)$ of resin composites. This study aimed to evaluate the effect of mechanical brushing time of dentifrices with different abrasiveness on $\Delta \mathrm{E}$ and $\Delta \mathrm{Ra}$ of nanofilled (Z350, 3M ESPE) and nanohybrid (Tetric N-Ceram, Ivoclar Vivadent) resin composites. Sixteen specimens ( $12 \mathrm{~mm}$ diameter $\times 2 \mathrm{~mm}$ thick) were fabricated using a white Teflon matrix of each resin composite and a ceramic (IPS e.max Ceram, Ivoclar Vivadent), used as control. After initial color readouts on white backgrounds (Spectrophotometer PCB 6807, Byk Gardner), with D65 standard illuminant, and surface roughness (Rugosimeter Surfcorder SE 1700, Kosalab) with cut-off $=0.8 \mathrm{~mm}$ and speed $=0.25 \mathrm{~mm} / \mathrm{s}$, specimens were assigned $(n=8)$ according to the abrasiveness of the dentifrices: RDA* 68 (Colgate) and RDA* 180 (Colgate Total Plus Whitening). Specimens were submitted to mechanical brushing $(58,400$ cycles) and after every 14,600 cycles ( 1 year of brushing by a healthy individual), new color and surface roughness readouts were taken. Color stability was calculated by CIEDE2000. Data were analyzed by 3-way repeated measures ANOVA and Bonferroni test $(p<0.05)$, and demonstrated that the dentifrice abrasiveness $(p=0.02)$ and brushing time $(p<0.0001)$ affected the $\Delta E$ of nanofilled resin composite. There was no difference on surface roughness of materials $(p=0.6752)$ or brushing time $(p=0.7997)$. In conclusion, the longer the brushing time and dentifrice abrasiveness, the greater the color change of the nanofilled resin composite. The surface roughness was not influenced by dentifrice abrasiveness.
\end{abstract}

Key Words: resin composites, dentifrice, abrasiveness, color, surface roughness.

\section{Introduction}

The quest for esthetics by both patients and dentists has led to the continuous improvement of Dentistry as regards innovations in restorative and rehabilitating materials and/ or techniques, leading to restorations with an appearance closer to natural teeth. The characteristics of simulating dental structure color, translucence and surface smoothness has made resin composite the first choice among the restorative materials used in Dentistry.

In the chronology of resin composite development, a constant search for improvements in the physicalmechanical and chemical properties as well as esthetics has been observed. Among the improvements attained in contemporary resin composites are properties such as lower polymerization shrinkage and greater compressive strength, they are easier to manipulate and make it possible to obtain anatomically correct restorations (1). Nevertheless, color stability and surface roughness were still a problem inherent to the material and researchers are unanimous to recognize that direct restorations performed with conventional composites undergo changes in color (1-3) and surface roughness (4-7) with time.

The roughness of a restoration concerns the finest surface irregularities that occur due to the characteristics of material (1), and the restorative (6) and polishing procedures $(5,6)$. The chemical structure of resin composite - type of used oligomers or monomers, concentration/types of activators, initiators, inhibitors, oxidation of double carbon links and the particle/resin matrix bonding system $(2,3)$, and filler particle characteristics have a direct impact on the surface roughness and staining of the resin composite (2).

Color change of resin composites also occurs due to the type of light used in light activation, time of exposure and resin matrix $(1,2,8)$ It may also be influenced by incomplete polymerization of the material (1), lower degree of conversion (3), water sorption (8), diet and oral hygiene (9).

The effect of brushing on the surface roughness of resin composites is a significant factor in determining the performance of materials. As a result of this abrasive treatment, the greater the relative abrasiveness of the dentifrice, the greater will be the surface roughness of resin materials (4-6), consequently affecting the esthetics of the restoration (7-9). Different from resin composites, ceramic materials - considered inert - do not undergo great alterations during their useful life in the oral cavity (7).

Considering the foregoing and the hypothesis that the greater the dentifrice abrasiveness and brushing time, the greater the color change and surface roughness of resin 
composites, the aim of this in vitro study was to evaluate the effect of brushing time and dentifrice abrasiveness on the color stability and surface roughness of esthetic restorative materials.

\section{Material and Methods}

The materials used in this study are described in Table 1.

Sixteen specimens of each material were obtained using a white Teflon matrix ( $12 \mathrm{~mm}$ diameter $\times 2 \mathrm{~mm}$ thick). The ceramic specimens were considered as a control group.

Resin composite specimens (shade A3) were obtained according to the incremental technique, the last increment covered with a glass slide to allow excess resin runoff and protect against formation of an oxygen inhibition layer. The specimens were photoactivated for $20 \mathrm{~s}$ using a LED light-emitting unit (FlashLite 1401; Discus Dental, Culver City, CA, USA), radiant emittance $\geq 1100 \mathrm{~mW} / \mathrm{cm}^{2}$, wavelength range between 460 and $480 \mathrm{~nm}$ ). Next, they were polished with silicon carbide $(\mathrm{SiC})$ papers (Norton Abrasives, Guarulhos, SP, Brazil) of decreasing abrasiveness (\#600, \#1200 and \#2000 grit). The thickness of specimens was measured with a digital caliper (Digimess Precision Measuring Instruments, São Paulo, SP, Brazil).

Ceramic specimens (A3) were fabricated according to the two-firing condensation technique (Phoenix; Ceramco, Burlington, VT, USA) at an initial temperature of $450{ }^{\circ} \mathrm{C}$ and final temperature of $755^{\circ} \mathrm{C}$ in vacuum, in accordance with the manufacturer's guidelines. After the last firing, specimens were polished with $\mathrm{SiC}$ papers (Norton) of decreasing abrasiveness (\#100, \#320, \#1200 and \#2000 grit), 30 s for each grit, and their dimensions were measured with a digital caliper. After this, the specimens of all materials were stored in distilled water at $37^{\circ} \mathrm{C}$ for $24 \mathrm{~h}$.

Next, initial color readoutsweretaken (Spectrophotometer PCB 6807, Byk Gardner, Geretsried, Germany) on white background ( $L=94.86 ; a=0.84 ; b=0.11 ; Y=87.29)$ and measured at $45^{\circ}$, with D65 standard illuminant, according to $\mathrm{CIE} \mathrm{L}^{*} \mathrm{a}^{*} \mathrm{~b}^{*}$ coordinates. This equipment has 30 LED lamps with 10 different colors arranged in a circle. The axes $a^{*}$ and $\mathrm{b}^{*}$ are chromaticity coordinates, $\mathrm{a}^{*}$ axis representing the color redness or greenness and the $b^{*}$ axis representing the color yellowness or blueness. The $L^{*}$ axis, perpendicular to $a^{*}$ and $b^{*}$, represents the perceived color lightness.

Surface roughness (Rugosimeter Surfcorder SE 1700; Kosakalab, Tokyo, Japan) was obtained in three measurements (cut-off $=0.8 \mathrm{~mm}$; speed $=0.25 \mathrm{~mm} / \mathrm{s}$ ) on different surfaces of each specimen and the mean value was considered the initial surface roughness readout.

Specimens were randomly allocated into 2 groups $(n=8)$, according to the abrasiveness of the dentifrices (Table 2). Mechanical brushing (Pepsodent; MAVTEC - Com. Peças, Acess. e Serv. Ltda. ME, Ribeirão Preto, SP, Brazil) was performed with soft toothbrushes (Tek; Johnson \& Johnson Ind. Com Ltda., São José dos Campos, SP, Brazil) - one per specimen. The toothbrush heads were cut off and fitted into the clamp of the apparatus. Each brush/clamp set resulted in a final weight of $200 \mathrm{~g}$.

Each specimen was fitted into a central circular hole of a plexiglass slide (Acrilpress Artifacts Ltda, Ribeirão Preto, SP, Brazil) to allow adaptation and fixation during mechanical brushing (course $=3.8 \mathrm{~cm}$; speed $=356 \mathrm{rpm}$ ). The dentifrices were diluted in distilled water (ratio 1:1).

Specimens were individually submitted to a total of 58,400 cycles of mechanical brushing, corresponding to a

Table 1. Materials used in the study

\begin{tabular}{|c|c|c|c|c|c|c|}
\hline Materail & Manufacturer & Composition & $\begin{array}{c}\text { Mean } \\
\text { particle size }\end{array}$ & $\begin{array}{l}\% \text { Filler } \\
\text { (by vol) }\end{array}$ & $\begin{array}{l}\text { Mean color readouts } \\
\text { (baseline) }\end{array}$ & $\begin{array}{c}\text { Mean SR } \\
\text { readouts (baseline) }\end{array}$ \\
\hline $\begin{array}{l}\text { Z350 } \\
\text { (nanofilled) }\end{array}$ & $\begin{array}{c}\text { 3M ESPE, } \\
\text { St Paul, MN, USA }\end{array}$ & $\begin{array}{c}\text { Bis-GMA, Bis-EMA, } \\
\text { UDMA, TEGDMA, } \\
\text { zirconia and silica }\end{array}$ & $\begin{array}{l}5-20 \mathrm{~nm} n . \text { ag. } \\
0.6-4 \mu \mathrm{m} \text { ag. }\end{array}$ & $59.5 \%$ & $\begin{array}{c}\mathrm{L}^{*}=69.00 \\
\mathrm{a}^{*}=7.48 \\
\mathrm{~b}^{*}=23.53\end{array}$ & $\mathrm{Ra}=0.177$ \\
\hline $\begin{array}{l}\text { Tetric N-Ceram } \\
\text { (nanohybrid) }\end{array}$ & $\begin{array}{l}\text { Ivoclar Vivadent AG, } \\
\text { Schaan, Liechtenstein }\end{array}$ & $\begin{array}{c}\text { 19-20\% Bis-GMA, } \\
\text { Bis-EMA, UDMA } \\
\text { 80-81\% barium glass, } \\
\text { ytterbium trifluoride, } \\
\text { mixed oxides, and copolymer }\end{array}$ & $\begin{array}{c}40 \mathrm{~nm} \\
3000 \mathrm{~nm}\end{array}$ & $55-57 \%$ & $\begin{aligned} \mathrm{L}^{*} & =68.42 \\
\mathrm{a}^{*} & =8.41 \\
\mathrm{~b}^{*} & =23.23\end{aligned}$ & $\mathrm{Ra}=0.234$ \\
\hline $\begin{array}{l}\text { IPS e.max } \\
\text { Ceram } \\
\text { (ceramic) }\end{array}$ & $\begin{array}{l}\text { lvoclar Vivadent AG, } \\
\text { Schaan, Liechtenstein }\end{array}$ & $\begin{array}{c}60 \% \text { silicon dioxide, } \\
40 \% \text { aluminum trioxide, } \\
\text { zinc peroxide, sodium oxide, } \\
\text { potassium oxide, } \\
\text { zirconium oxide, calcium oxide, } \\
\text { phosphorus pentoxide, } \\
\text { fluorides and pigments. }\end{array}$ & - & - & $\begin{aligned} \mathrm{L}^{*} & =68.82 \\
\mathrm{a}^{*} & =4.67 \\
\mathrm{~b}^{*} & =20.64\end{aligned}$ & $\mathrm{Ra}=0.366$ \\
\hline
\end{tabular}

n.a. = non-agglomerated; a. = agglomerated; SR = surface roughness; Bis-GMA: Bisphenol A glycol dimethacrylate; Bis-EMA = Ethoxylated bisphenol A glycol dimethacrylate; UDMA = Urethane dimethacrylate; TEGDMA = Triethylene glycol dimethacrylate. 
4-year exposure to brushing by a healthy individual (10). After every 14,600 cycles, which corresponded to 1 year of brushing, the machine was switched off, the specimens were dried with absorbent papers to remove surface debris and submitted to new color and surface roughness readouts. The roughness readouts were performed perpendicular to the movement of brushing to record the wear resulting from this abrasive treatment. Both toothbrush head and the dentifrice solution were replaced after every cycle of brushing.

After this, new color readings were taken and the color change for each group was calculated by CIEDE2000 color change $\left(\Delta \mathrm{E}_{00}\right)$ using the equation:$$
\Delta \mathrm{E}_{00}=\left[\left(\Delta \mathrm{L}^{\prime} / \mathrm{K}_{\mathrm{L}} \mathrm{S}_{\mathrm{L}}\right)^{2}+\left(\Delta \mathrm{C}^{\prime} / \mathrm{KcSc}\right)^{2}+\left(\Delta \mathrm{H}^{\prime} / \mathrm{K}_{\mathrm{H}} \mathrm{S}_{\mathrm{H}}\right)^{2}+\mathrm{R}_{\mathrm{T}}\left(\Delta \mathrm{C}^{\prime} /\right.\right.
$$ $\left.\mathrm{KcSc})^{2}\left(\Delta \mathrm{H}^{\prime} / \mathrm{K}_{\mathrm{H}} \mathrm{S}_{\mathrm{H}}\right)^{2}\right]^{1 / 2}$}

where $\Delta \mathrm{L}^{\prime}, \Delta \mathrm{C}^{\prime}$, and $\Delta \mathrm{H}^{\prime}$ are the differences in lightness, chroma and hue for a pair of samples in CIEDE2000 and $R_{T}$ is a function (the so-called rotation function) that accounts for the interaction between chroma and hue differences in the blue region. Weighting functions, $\mathrm{S}_{\mathrm{L}} \mathrm{Sc}$, and $\mathrm{S}_{\mathrm{H}}$ adjust the total color difference for variation in the location of the color difference pair in $\mathrm{L}^{*}, \mathrm{a}^{*}$ and $\mathrm{b}^{*}$ coordinates and the parametric factors, $\mathrm{K}_{\mathrm{L}} \mathrm{Kc}$ and $\mathrm{K}_{\mathrm{H}}$ are correction terms for experimental conditions as described by Sharma et al. (11).

Surface roughness alteration $(\Delta R a)$ was calculated using the equation:

$\Delta R a=R a_{f}-R a_{i}$

where $R a_{i}$ is the initial and $R a_{f}$ the final roughness measurement.

After checking normality of the results, the values were submitted to statistical analysis by 3-way ANOVA for repeated measures and the Bonferroni test at a significance level of $5 \%$.

\section{Results}

The studied resin composites presented similar baseline color readouts, as may be seen in Table 1 .

Comparisons of the mean color change $(\Delta \mathrm{E})$ values are shown in Table 3. There was no significant color change
( $p=0.9331)$ for ceramic and nanohybrid resin composites regardless of dentifrice abrasiveness, except for the nanohybrid resin composite, which showed higher $\Delta \mathrm{E}$ $(p=0.0332)$ after brushing with $\mathrm{RDA}^{*} 180$, compared with $\mathrm{RDA}^{*} 68$, after 4 cycles of brushing.

The greater dentifrice abrasiveness, the greater the color change $(p<0.0001)$ of the nanofilled resin composite, except after the first brushing cycle; at this time, no difference was observed in $\Delta E$ between both dentifrices $(p=0.4253)$.

Regarding the nanofilled resin composite, mean $\Delta \mathrm{E}$ values increased from the first to third cycles for both dentifrices; but when dentifrice $\mathrm{RDA}^{*} 68$ was used, $\Delta \mathrm{E}$ decreased significantly $(p=0.0006)$ after the fourth cycle compared to first and third cycles. For the RDA* 180 dentifrice, there was a significant color change $(p=0.0140)$ between the first and third cycles, and no difference $(p=0.9581)$ in $\Delta E$ after all other cycles.

The nanohybrid resin composite after brushing with dentifrice $\mathrm{RDA}^{*} 68$ resulted in greater and significant ( $p=0.0450) \Delta E$ only after the third cycle, compared to second cycle. There was no difference among other comparisons $(\mathrm{p}=0.9910)$. After brushing with $\mathrm{RDA}^{*} 180$ dentifrice, $\Delta \mathrm{E}$ was higher after the last cycle, compared to second and third cycles, $(p=0.0013$ and $p=0.0073$, respectively), which did not show difference $(p=0.9425)$ between them and the first cycle $(p=0.0584 / p=0.1950)$, which did not present difference $(p=0.5410)$ in comparison with last cycle.

Color data of the ceramic showed no significant difference $(p>0.05)$ in $\Delta E$ values between all brushing cycles when the tested dentifrices were used.

Comparing the materials (Fig. 1), after all cycles of brushing with dentifrice $\operatorname{RDA}^{*} 68$, the nanofilled resin composite demonstrated higher values for $\Delta E(p<0.0001)$ than other materials, which did not present difference among them $(p=0.9331)$. There was no difference $(p>0.05)$ between materials after brushing with dentifrice RDA* 180 .

Table 4 shows the mean surface roughness values $(\Delta R a)$ of the different materials considering the brushing cycles and dentifrices. The $\Delta$ Ra values of ceramic and nanofilled resin composite did not differ significantly ( $p>0.9999)$ for every brushing cycle when the dentifrices were evaluated.

Table 2. Groups formed according to the treatments according to the abrasiveness of the dentifrices

\begin{tabular}{|c|c|c|c|c|}
\hline Group & Treatment & Dentifrice & Composition & Manufacturer \\
\hline 1 & $\begin{array}{l}\text { Brushing Dentifrice } \\
\qquad \text { RDA* }^{*} 68\end{array}$ & Colgate & $\begin{array}{l}\text { Water, calcium carbonate, sorbitol, sodium lauryl sulphate, } \\
\text { sodium monofluorophosphate, aroma, cellulose gum, } \\
\text { sodium silicate, sodium bicarbonate, sodium saccharin, } \\
\text { xanthan gum, methylparaben and propylparaben }\end{array}$ & $\begin{array}{l}\text { Colgate - Palmolive } \\
\text { Company, São Bernardo } \\
\text { do Campo, SP, Brazil }\end{array}$ \\
\hline 2 & $\begin{array}{l}\text { Brushing Dentifrice } \\
\qquad \text { RDA }^{*} 180\end{array}$ & $\begin{array}{l}\text { Colgate Total } \\
\text { Plus Whitening }\end{array}$ & $\begin{array}{l}\text { Water, sorbitol, hydrated silica, sodium lauryl sulphate, } \\
\text { copolymer, aroma, carrageenan, sodium hydroxide, } \\
\text { sodium fluoride, sodium saccharin and Triclosan }\end{array}$ & $\begin{array}{l}\text { Colgate - Palmolive } \\
\text { Company, São Bernardo } \\
\text { do Campo, SP, Brazil }\end{array}$ \\
\hline
\end{tabular}


Only the nanohybrid resin composite showed higher $\Delta \mathrm{Ra}$ values after the third brushing cycle when dentifrice RDA* 180 was used, different results ( $p=0.0002)$ after the first cycle.

Comparing the dentifrices for each material, there was no difference in $\Delta R$ Ra values, except for the nanohybrid resin composite brushed with RDA* $^{*} 180$, which presented higher $\triangle \mathrm{Ra}$ than $\mathrm{RDA}^{*} 68$ after the third $(\mathrm{p}<0.0001)$ and fourth ( $p=0.0078$ ) cycles.

When the materials were analyzed, dentifrice RDA* 68 was not able to significantly change ( $p>0.05)$ the surface roughness of the materials (Fig. 2). After brushing with $\mathrm{RDA}^{*} 180$, the nanohybrid resin composite presented higher values of $\Delta R a$, different $(p<0.05)$ from ceramic from the second to fourth cycles $(p=0.0191, p<0.0001$ and $p=0.0078$, respectively). There was no difference $(p>0.05)$ concerning the nanofilled resin composite for all cycles (Fig. 2).

\section{Discussion}

This study evaluated the color stability and surface roughness of two types of resin composites and a ceramic (control) submitted to mechanical brushing with dentifrices of RDA* abrasiveness 68 and 180 for up to 58,400 cycles, simulating 4 years of clinical brushing. Based on the results obtained in the present study, the hypothesis may be partially accepted, since the greater dentifrice abrasiveness

Table 3. Comparison (3-way ANOVA, repeated measures, Bonferroni, $p<0.05$ ) of $\Delta E$ means (S.D.) of materials according to the brushing time and the type of dentifrice.

\begin{tabular}{lccc}
\hline Material & Cycle & RDA $^{*} 68$ & RDA $^{*} 180$ \\
\hline $\begin{array}{l}\text { Z350 } \\
\text { (nanofilled) }\end{array}$ & 1 & $0.85(0.16)^{\mathrm{Ca}}$ & $0.61(0.34)^{\mathrm{Ba}}$ \\
& 3 & $1.15(0.20)^{\mathrm{Ba}}$ & $0.78(0.29)^{\mathrm{ABb}}$ \\
& 4 & $1.49(0.14)^{\mathrm{Aa}}$ & $0.87(0.21)^{\mathrm{Ab}}$ \\
& 1 & $0.51(0.23)^{\mathrm{ABa}}$ & $0.77(0.34)^{\mathrm{ABa}}$ \\
$\begin{array}{l}\text { Tetric N-Ceram } \\
\text { (nanohybrid) }\end{array}$ & 2 & $0.40(0.19)^{\mathrm{Ba}}$ & $0.82(0.31)^{\mathrm{ABb}}$ \\
& 3 & $0.61(0.23)^{\mathrm{Aa}}$ & $0.60(0.17)^{\mathrm{Ba}}$ \\
& 4 & $0.49(0.16)^{\mathrm{ABb}}$ & $0.88(0.32)^{\mathrm{Aa}}$ \\
& & & \\
& 1 & $0.39(0.25)^{\mathrm{Aa}}$ & $0.52(0.44)^{\mathrm{Aa}}$ \\
$\begin{array}{l}\text { IPS e.max Ceram } \\
\text { (ceramic) }\end{array}$ & 2 & $0.39(0.24)^{\mathrm{Aa}}$ & $0.48(0.27)^{\mathrm{Aa}}$ \\
& 3 & $0.43(0.23)^{\mathrm{Aa}}$ & $0.54(0.29)^{\mathrm{Aa}}$ \\
& 4 & $0.54(0.21)^{\mathrm{Aa}}$ & $0.62(0.31)^{\mathrm{Aa}}$ \\
\hline
\end{tabular}

Different letters, lowercase in rows and uppercase in columns, indicate statistically significant difference $(\mathrm{p}<0.05)$. and brushing time, the greater the color change found for the nanofilled resin composite; there was no difference in color stability for the other materials. Regarding the surface roughness, the materials were not affected by dentifrice abrasiveness and brushing time.

Clinically, the aim of brushing with dentifrices is to polish tooth and restorations surfaces (4), in order to obtain smooth surfaces and leaving them less subject to staining (8). Obviously, these procedures have a direct influence on the esthetics and longevity of the material, because it is almost impossible to achieve restorations with perfectly smooth surfaces after they are performed (12).

The mechanical brushing method is suitable for simulating normal oral hygiene procedures, because it standardizes the applied force, distance and frequency of brushing on the samples $(6,8)$, imposing a process of wear on the material (13). However, this abrasion is not the only factor to which restorative materials are subjected in the oral cavity. Brushing may cause a polishing action, depending on the interaction between the sample surfaces and the abrasive particles in the dentifrice (4).

In the present study, brushing was simulated for up to 4 years, with color and roughness evaluations performed after every 1 year simulated period. Considering that in normal clinical conditions, 40 brushing cycles per day are applied (10), in one year the number of cycles corresponds

Table 4. Comparison (3-way ANOVA, repeated measures, Bonferroni, $p<0.05)$ of mean values (S.D.) of surface roughness $(\Delta R a)$ of materials according to the brushing time and the type of dentifrice

\begin{tabular}{lccc}
\hline Material & Cycle & RDA $^{*} 68$ & RDA $^{*} 180$ \\
\hline $\begin{array}{lcc}\text { Z350 } \\
\text { (nanofilled) }\end{array}$ & 1 & $0.017(0.04)^{\mathrm{aA}}$ & $0.080(0.07)^{\mathrm{aA}}$ \\
& 3 & $0.026(0.02)^{\mathrm{aA}}$ & $0.112(0.10)^{\mathrm{aA}}$ \\
& 4 & $0.059(0.03)^{\mathrm{aA}}$ & $0.170(0.13)^{\mathrm{aA}}$ \\
& 1 & $0.017(0.12)^{\mathrm{aA}}$ & $0.139(0.11)^{\mathrm{aA}}$ \\
$\begin{array}{l}\text { Tetric N-Ceram } \\
\text { (nanohybrid) }\end{array}$ & 2 & $0.048(0.13)^{\mathrm{aA}}$ & $0.170(0.13)^{\mathrm{aA}}$ \\
& 3 & $0.042(0.10)^{\mathrm{bA}}$ & $0.333(0.07)^{\mathrm{aA}}$ \\
& 4 & $0.055(0.13)^{\mathrm{bA}}$ & $0.248(0.14)^{\mathrm{aAB}}$ \\
& & & \\
& 1 & $0.064(0.27)^{\mathrm{aA}}$ & $0.036(0.10)^{\mathrm{aA}}$ \\
$\begin{array}{l}\text { IPS e.max Ceram } \\
\text { (ceramic) }\end{array}$ & 2 & $0.087(0.28)^{\mathrm{aA}}$ & $0.003(0.14)^{\mathrm{aA}}$ \\
& 3 & $0.090(0.29)^{\mathrm{aA}}$ & $0.003(0.15)^{\mathrm{aA}}$ \\
& 4 & $0.091(0.25)^{\mathrm{aA}}$ & $0.027(0.18)^{\mathrm{aA}}$ \\
\hline
\end{tabular}

Different letters, lowercase in rows and uppercase in columns, indicate statistically significant difference $(\mathrm{p}<0.05)$. 
to 14,600 . According to some authors $(4,14), 10,000$ cycles would be sufficient to simulate one year of brushing. Other studies (4-7) have proved that this is an adequate method that allows evaluating the efficiency of different dentifrices and mean roughness of restorative materials.

The larger the abrasive particle size, the greater the abrasiveness of the dentifrice (15) and the more effective the removal of staining from pigmented structures (16). The whitening dentifrices (RDA* 180) contain specific chemical components in their formulation, which reduce staining (5) and were designed to maximize cleaning and minimizing wear (17), irrespective of having any physical effect on the material.

The type of abrasive agent can influence the abrasiveness of materials. In the present study, the RDA* 180 dentifrice has silica in its composition (Table 2), which is less abrasive than calcium carbonate (15), component of dentifrice $\mathrm{RDA}^{*} 68$. This may justify the results found in this study, that demonstrated higher $\triangle E$ values after brushing with dentifrices RDA* 68 than with RDA* 180 for the nanofilled resin composite.

As regards the influence of brushing time on color stability, $\Delta \mathrm{E}$ value did not change, except for the nanofilled resin composite, which exhibited higher $\Delta \mathrm{E}$

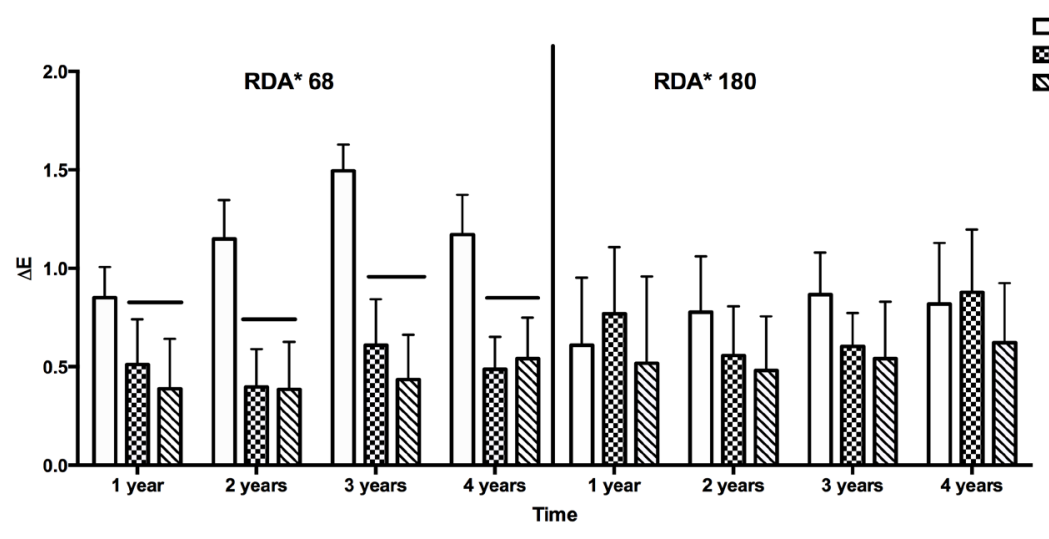

Figure 1. Comparison (3-way ANOVA, repeated measures, Bonferroni, $\mathrm{p}<0.05$ ) of $\Delta$ E mean values of materials according to the brushing time and the type of dentifrice. Horizontal line over the columns indicates no significant difference $(p<0.05)$. For all comparisons of RDA* 180, $p>0.05$.

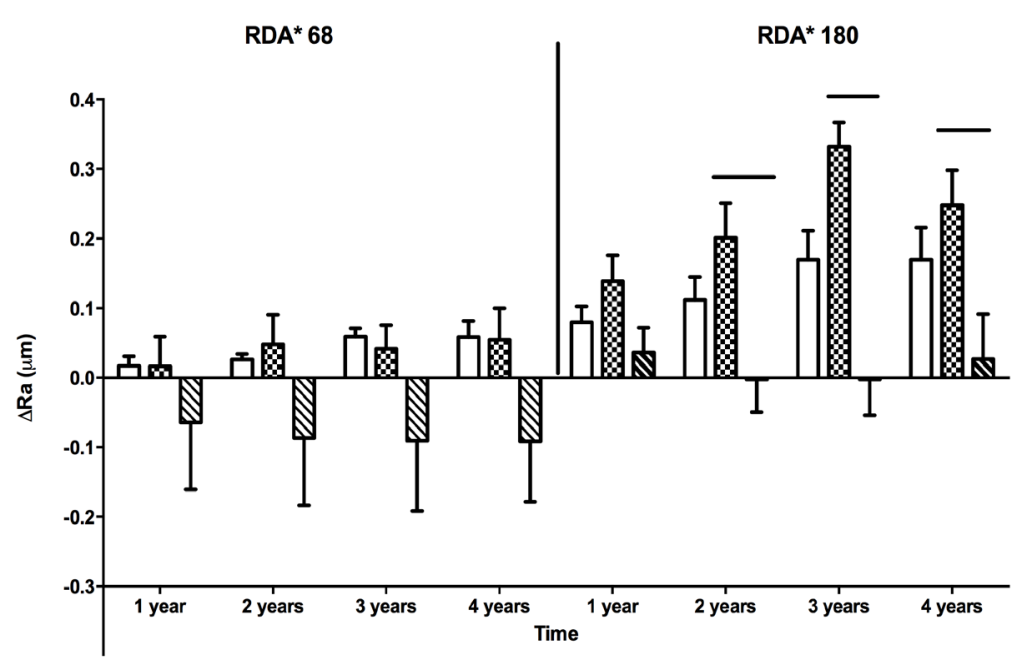

Figure 2. Comparison (3-way ANOVA repeated measures, Bonferroni, $p<0.05$ ) of $\Delta$ Ra mean values of materials according to the brushing time and type of dentifrice. Horizontal line over the columns indicates significant difference $(p<0.05)$. For all comparisons of RDA* 68, $p>0.05$. values up to the third cycle of brushing for both dentifrices. It is known that the surface of a resin composite presents a higher resin content when photopolymerized under a certain pressure against a smooth surface (18), such as the placement of a glass slide. With the increase in the number of brushing cycles, it is reasonable to believe that there was a gradual removal of this matrix-rich layer (5). This may have contributed to the color change of the nanofilled resin composite after the third cycle, in which the superficial staining may have been removed by wear (19).

Some studies have shown that the type of monomer interferes in the level of water sorption of the resin composite $(1,19)$ and this may lead to color change (12). Due to the low conversion levels of the TEGDMA monomer, it is predisposed to water sorption, increasing the solubility of the polymer formed between the polymer matrix bonds (20), causing deterioration of this structure and of the matrix/filler particle interface, resulting in greater color change (9). The higher 
the degree of water sorption of a resin composite, the lower the color stability, due to the increase in the free volume of formed polymer. Consequently, more space is available for diffusion of water molecules into the polymeric structure (3). This phenomenon is called composite plasticization (21) and it causes softening of the polymer matrix, promoting a greater color change of the resin composite (9).

As regards the filler particles, resin composites with larger particles are more susceptible to water sorption and color change (22), a phenomenon explained by the weak bond at the matrix/filler interface, which is broken by water sorption, changing the manner in which light is dispersed by the particles (20). In addition, composites with low concentration of filler particles present higher $\Delta$ E values (22).

In the present study, the nanofilled resin composite, which has agglomerated particle sizes from 0.6 to $1.4 \mu \mathrm{m}$ ( $59.5 \%$ by volume), presented the highest levels of $\Delta \mathrm{E}$ when submitted to brushing with dentifrice RDA* 68 in comparison with the nanohybrid resin composite, which has particle sizes ranging from 0.04 to $3.0 \mu \mathrm{m}$ ( 55 to $57 \%$ by volume). Therefore, the results found in the present study are not in agreement with those of the previously cited authors. Some authors have shown that the percentage of filler particles by volume per se may not explain the variations in water sorption and discoloration of a resin composite $(2,3,20)$.

The nanofilled resin composite has aggregated filler particles and glass particles that are susceptible to porosities with the absorption of water, resulting in staining and color change $(9,12)$. Therefore, considering that the nanofilled resin composite contains TEGDMA and this leads to greater degradation of the matrix/filler particle bond, the action of brushing on this resin composite may have caused greater removal of these particles from the surface (23), diminishing its color stability.

Abrasion gradually removes the resin matrix among the filler particles of composites; the unsupported filler particles are easily eliminated, leaving a particle-free resin layer which is rapidly abraded and the process becomes continuous (24). However, the influence of the polymer degree of conversion and the volume ratio of filler in the matrix on the resistance to abrasion of resin composites (24). Since the agglomerated particle sizes of nanoparticle resin composites are smaller than $2 \mu \mathrm{m}$, the abrasion process is comparatively slower than for hybrid resin composites (14).

Although studies have found no correlation between resin composite particle size and surface roughness after brushing $(14,25)$, as related in the present study, it was expected that the nanohybrid resin composite, being a composite with larger particles, would present a higher surface roughness after mechanical brushing (6) due to the removal of superficial particles of composite.

When the resin composite is a hybrid type, this removal of particles would leave pores as large as the size of its particles in the material surface. As the nanosized resin composite has smaller particles, the removal of particles would leave smaller pores. However, one has to consider that the nanohybrid resin composite has particles sizes ranging from 40 to $3000 \mathrm{~nm}$, whereas the nanofilled resin composite has particles of 5 to $20 \mathrm{~nm}$ in size, but they are agglomerated into particle sizes that reach 600 to 1400 $\mathrm{nm}$, which exceeds the sizes of the smaller particles in the nanohybrid resin composite.

The resin composites did not present differences in surface roughness after brushing with different type of dentifrice. This may be justified by the fact that the abrasion is not directly related to the whitening agent and depends on the set of components in the dentifrice formulation (5).

Other results may be explained by the size and distribution of the nanohybrid resin composite filler particles that allow for a more consistent polishing of the resin composite (6). This is because smaller and more homogeneous filler particles would be closer to one another, thus reducing the amount of organic matrix that may be exposed and diminishing the wear after brushing (25). Furthermore, although the exposure of filler particles occurs during the procedure of polishing by brushing, the particles of the nanohybrid resin composite, even the larger ones, may have been worn along with the polymer matrix during the brushing cycles, instead of being removed (9).

A limitation of the study was that brushing was performed with dentifrice diluted in distilled water. One understands that clinically, this dilution occurs in saliva, and its special properties such as the presence of enzymes, specific proteins and ions, may diminish the effect of toothbrush roughness on the samples.

It was concluded that the longer the mechanical brushing time and the dentifrice abrasiveness, the greater the color change of nanofilled resin composites. The length of brushing time and dentifrice abrasiveness did not alter the surface roughness of resin composites.

\section{Resumo}

A abrasividade do dentifricio e o tempo de escovação podem aumentar a alteração de cor $(\Delta E)$ e rugosidade de superfície $(\Delta R a)$ das resinas compostas. Este estudo teve como objetivo avaliar o efeito do tempo de escovação mecânica com dentifricios de diferentes abrasividades, sobre o $\Delta \mathrm{E}$ e a $\Delta \mathrm{Ra}$ das resinas compostas (nanoparticulada, Z350, 3M ESPE e nanohibrida, Tetric N-Ceram, Ivoclar Vivadent). Dezesseis amostras (12 $\mathrm{mm}$ de diâmetro $\times 2 \mathrm{~mm}$ de espessura) foram obtidas utilizando uma matriz de teflon branca, de cada resina composta e uma cerâmica (IPS e.max Ceram, Ivoclar Vivadent), considerada como controle. Após as leituras iniciais de cor sobre fundo branco (Espectrofotômetro PCB 6807, Byk Gardner), com iluminante padrão D65, e de rugosidade de superfície (Rugosímetro Surfcorder SE 1700, Kosalab), com cut-off $=0,8$ $\mathrm{mm}$ e velocidade $=0,25 \mathrm{~mm} / \mathrm{s}$, as amostras foram separadas $(n=8)$ de 
acordo com a abrasividade dos dentifrícios: RDA* 68 (Colgate) e RDA* 180 (Colgate Total Plus Whitening). Amostras foram submetidas a escovação mecânica (58.400 ciclos), sendo que a cada 14.600 ciclos (1 ano de escovação por um indivíduo saudável), novas leituras de cor e rugosidade de superficie foram realizadas. A estabilidade de cor foi calculada segundo CIEDE2000. Os dados foram analisados (3-way ANOVA medidas repetidas, teste de Bonferroni, $p<0,05)$, e demonstrou-se que a abrasividade dos dentifricios $(p=0,02)$ e o tempo de escovação $(p<0,0001)$ afetaram o $\Delta E$ da resina composta nanoparticulada. A rugosidade de superfície não foi influenciada pela abrasividade dos dentifricios $(p=0,6752)$ ou tempo de escovação $(p=0,7997)$. Concluiu-se que quanto maior o tempo de escovação mecânica e a abrasividade do dentifrício, maior a alteração de cor da resina composta nanoparticulada. A rugosidade de superficie não foi influenciada pela abrasividade do dentifrício.

\section{Acknowledgements}

This study was supported by São Paulo Research Foundation (Brazil) Grant No. 2012/13342-4.

\section{References}

1. Janda R, Roulet JK, Kaminsky M, Steffin G, Latta M. Color stability of resin matrix restorative materials as a function of the method of light activation. Eur J Oral Sci 2004;112:280-285.

2. Pires-de-Souza F de C, Garcia L da F, Hamida HM, Casemiro LA. Color stability of composites subjected to accelerated aging after curing using either a halogen or a light emitting diode source. Braz Dent J 2007;18:119-123.

3. Mundim FM, Pires-de-Souza FC, Garcia LF, Consani S. Colour stability, opacity and cross-link density of composites submitted to accelerated artificial aging. Eur J Prosthodont Restor Dent 2010;18:89-93.

4. Wang L, Garcia FC, Amarante Araujo P, Franco EB, Mondelli RF. Wear resistance of packable resin composites after simulated toothbrushing test. J Esthet Restor Dent 2004;16:303-314.

5. Amaral CM, Rodrigues JA, Erhardt MC, Araujo MW, Marchi GM, Heymann $\mathrm{HO}$, et al.. Effect of whitening dentifrices on the superficial roughness of esthetic restorative materials. J Esthet Restor Dent 2006;18:102-108.

6. da Costa J, Adams-Belusko A, Riley K, Ferracane JL. The effect of various dentifrices on surface roughness and gloss of resin composites. J Dent 2010;38:123-128.

7. Heintze SD, Forjanic M, Ohmiti K, Rousson V. Surface deterioration of dental materials after simulated toothbrushing in relation to brushing time and load. Dent Mater 2010;26:306-319.

8. Ferracane JL. Hygroscopic and hydrolytic effects in dental polymer networks. Dent Mater 2006;22:211-222.

9. Nasim I, Neelakantan P, Sujeer R, Subbarao CV. Color stability of microfilled, microhybrid and nanocomposite resins - an in vitro study. J Dent 2010;38:137-142.
10. Wiegand A, Kuhn M, Sener B, Roos M, Attin T. Abrasion of eroded dentin caused by toothpaste slurries of different abrasivity and toothbrushes of different filament diameter. J Dent 2009;37:480-484

11. Sharma G, Wu W, Dalal EN. The CIEDE2000 color-difference formula: implementation notes, supplementary test data, and mathematical observations. Color Res Appl 2005;30:21-30.

12. Choi MS, Lee YK, Lim BS, Yang HC. Changes in surface characteristics of dental resin composites after polishing. J Mater Sci 2005;16:347-353.

13. Mondelli RF, Wang L, Garcia FC, Prakki A, Mondelli J, Franco EB, et al.. Evaluation of weight loss and surface roughness of compomers after simulated toothbrushing abrasion test. J Appl Oral Sci 2005;13:131135.

14. Suzuki T, Kyoizumi H, Finger WJ, Kanehira M, Endo T, Utterodt A, et al.. Resistance of nanofill and nanohybrid resin composites to toothbrush abrasion with calcium carbonate slurry. Dent Mater J 2009;28:708-716.

15. Camargo IM, Saiki M, Vasconcellos MB, Avila DM. Abrasiveness evaluation of silica and calcium carbonate used in the production of dentifrices. J Cosmet Sci 2001;52:163-167.

16. Koertge TE, Brooks CN, Sarbin AG, Powers D, Gunsolley JC. A longitudinal comparison of tooth whitening resulting from dentifrice use. J Clin Dent 1998;9:67-71.

17. Joiner A. Whitening toothpastes: a review of the literature. J Dent 2010;38:17-24.

18. Stanford WB, Fan PL, Wozniak WT, Stanford JW. Effect of finishing on color and gloss of composites with different fillers. J Am Dent Assoc 1985;110:211-213.

19. Roselino LM, Cruvinel DR, Chinelatti MA, Pires-de-Souza FC. Effect of brushing and accelerated ageing on color stability and surface roughness of composites. J Dent 2013;41:54-61.

20. Vichi A, Ferrari M, Davidson CL. Color and opacity variations in three different resin-based composite products after water aging. Dent Mater 2004;20:530-534.

21. Ferracane $\mathrm{JL}$, Berge $\mathrm{HX}$, Condon JR. In vitro aging of dental composites in water - effect of degree of conversion, filler volume, and filler/ matrix coupling. J Biomed Mater Res 1998;42:465-472.

22. Lee YK, Powers JM. Color changes of resin composites in the reflectance and transmittance modes. Dent Mater 2007;23:259-264.

23. Hu X, Marquis PM, Shortall AC. Influence of filler loading on the twobody wear of a dental composite. J Oral Rehabil 2003;30:729-737.

24. Condon JR, Ferracane JL. Factors affecting dental composite wear in vitro. J Biomed Mater Res 1997;38:303-313.

25. Garcia FC, Wang L, D'Alpino PH, Souza JB, Araújo PA, Mondelli RF. Evaluation of the roughness and mass loss of the flowable composites after simulated toothbrushing abrasion. Braz Oral Res 2004;18:156161. 